\title{
Estudio comparativo de tres bebidas formuladas con jícama (Smallanthus sonchifolius)
}

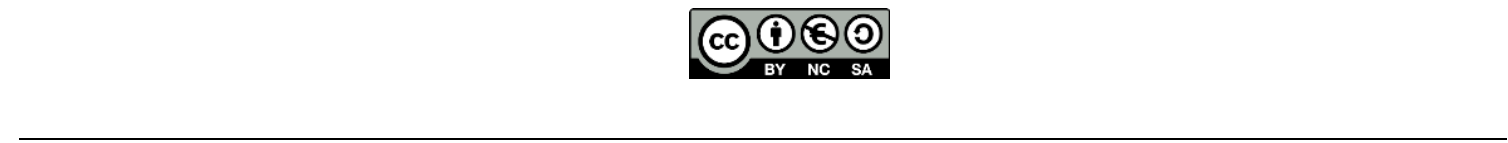

Comparative study of three beverages formulated with jicame (Smallanthus sonchifolius)

Darío Javier Baño Ayala. ${ }^{1}$, Jenny Lucrecia Velasco Gómez². Sandra Elizabeth López Sampedro, ${ }^{3} \&$ Luis Fernando Arboleda Alvarez ${ }^{4}$

DOI: https://doi.org/10.33262/concienciadigital.v3i3.1286

\begin{abstract}
.
Three drinks were formulated combining jicama with pineapple, babaco and passion fruit in order to provide an added value to the traditional use of the jicama and later evaluate the nutritional quality of the same, for this the physical and chemical microbiological analyzes were performed determining $\mathrm{pH},{ }^{\circ}$ Brix, titratable acidity, protein, total sugars, total coliforms, mesophilic aerobes. A DCA was used and Tukey's statistical test was applied with a niel of significance $p \leq 0,05$, finding that the nutritional properties of jicama juice with passion fruit showed better results due to its nutritional value $11.50{ }^{\circ} \mathrm{Brix}, 3.82$ $\mathrm{pH}, 13.19 \%$ total acidity, $0.54 \%$ protein, $0.78 \%$ ash and $38.62 \%$ total sugars The three formulations presented low microbiological loads for mesophiles and coliforms that do not exceed the maximum limits allowed by the INEN standards NTE 2337 for juices, pulps, concentrates, nectars, fruit and vegetable drinks.
\end{abstract}

Keywords: Jicame, passion fruit, functional, drink.

\footnotetext{
${ }^{1}$ Escuela Superior Politécnica de Chimborazo, Facultad de Ciencias Pecuarias. Riobamba, Ecuador.dbano@yahoo.es

${ }^{2}$ Profesional Independiente, Riobamba, Ecuador. wichyad@gmail.com

${ }^{3}$ Escuela Superior Politécnica de Chimborazo, Facultad de Ciencias Pecuarias. Riobamba, Ecuador. salopez@espoch.edu.ec

${ }^{4}$ Escuela Superior Politécnica de Chimborazo, Facultad de Ciencias Pecuarias. Riobamba, Ecuador. armando.paredes@espoch.edu.ec
} 


\section{Resumen.}

Se formularon tres bebidas combinando jícama con piña, babaco y maracuyá con el objeto de proporcionar un valor agregado al uso tradicional de la jícama y posteriormente evaluar la calidad nutritiva de las mismas, para esto se realizaron los análisis físico químicos y microbiológicos determinándose $\mathrm{pH}$, ${ }^{\circ}$ Brix, acidez titulable, proteína, azucares totales, coliformes totales, aerobios mesófilos. Se utilizó un DCA y se aplicó la prueba estadística de Tukey con un niel de significancia $\mathrm{p} \leq 0,05$, encontrándose que las propiedades nutricionales del jugo de jícama con maracuyá presentaron mejores resultados por su valor nutritivo $11,50{ }^{\circ} \mathrm{Brix}, 3,82 \mathrm{pH}, 13,19 \%$ acidez total, $0,54 \%$ de proteína, $0,78 \%$ cenizas y 38,62 \% azucares totales Las tres formulaciones presentaron bajas cargas microbiológicas para mesófilos y coliformes que no superan los límites máximos permitidos por las normas INEN NTE 2337 para Jugos, pulpas, concentrados, néctares, bebidas de frutas y vegetales.

Palabras clave: Jícama, maracuyá, funcional, bebida.

\section{Introducción.}

El Desde los inicios de la humanidad las frutas han sido parte de la alimentación humana, constituyéndose en un elemento importante para lograr una dieta sana y equilibrada, también aportan nutrientes esenciales para el organismo; por su parte las frutas son muy ricas en vitaminas $\mathrm{A}$ y $\mathrm{C}$, contienen además cantidades variables de sales minerales, magnesio, potasio, hierro, calcio, selenio, zinc. (Alvarez, E. 2011).

La Jícama (Smallanthus sonchifolius) es un tubérculo poco conocido que a pesar de ser un alimento rico en carbohidratos de reserva de almidón presenta varios beneficios y usos medicinales. Debido a la desvalorización y desconocimiento de la fruta es difícil obtenerla en micromercados, supermercados y tiendas de la ciudad, pero hay que considerar que es un alimento con múltiples funciones, ya que posee una amplia gama de compuestos bioactivos (antimicrobianos, antioxidantes y probióticos) que ejercen efectos benéficos sobre el organismo. (Manrique, 2003), siendo además una fuente importante de vitaminas y minerales que incrementan la capacidad oxidativa en el plasma (Rojas, 2001).

Por otra parte, se menciona (Díaz P, 2015) que la elaboración de jugos es una práctica muy antigua donde el consumo se va incrementando cada vez más, por tal razón se debe incentivar el consumo de nuevos productos como bebidas nutritivas por su aporte de vitaminas, minerales, agua y otros nutrientes. Cabe recalcar que, en los actuales mercados la búsqueda de la excelencia y la calidad se convierten en metas fundamentales para los productores de alimentos y bebidas (Parrilla C., 2002).

A pesar de que las frutas tienen una gran importancia en el mercado por su calidad nutricional, no se ha hecho ningún esfuerzo en las industrias ecuatorianas por procesar un jugo nutritivo siendo una alternativa de innovación y diversificación de producto, dando 
un valor agregado, aprovechando las propiedades sensoriales y nutritivas que ofrecen las mismas.

La elaboración de tres jugos con jícama combinado con tres frutas de características similares como son la piña, el babaco y el maracuyá cuyo fin fue obtener un producto mejorado y con buena aceptabilidad para darle mejor sabor a la bebida, considerando que la jícama es una fruta insípida, con múltiples beneficios, entonces al combinarla mejoramos sus características sensoriales con la adición de Ananas comosus (piña), Carica Pentágona (babaco) y Passiflora edulis (maracuyá).

\section{Metodología.}

Se seleccionaron y desinfectaron las frutas con kilol al 0,5\% mediante inmersión en la solución y reposo durante 5 minutos. Se peló y se cortó en cuadros pequeños para facilitar la extracción y mezclado, en las formulaciones se utilizó jícama, piña, maracuyá, babaco, agua, ácido cítrico y carboximetilcelulosa (CMC), el envasado se realizó a temperatura ambiente $20^{\circ} \mathrm{C}$, en envases de vidrio previamente lavados y enjuagados con agua caliente. La pasterización se llevó a cabo a una temperatura de $75^{\circ} \mathrm{C}$ durante 10 minutos, con la finalidad de inactivar los microorganismos patógenos.

Las unidades experimentales estuvieron conformadas por 15 litros de bebida de jícama, distribuidas en tres tratamientos con 5 repeticiones cada uno, siendo el tamaño de cada unidad experimental de un litro. Posteriormente se evaluó la composición físico química de cada formulación según los descrito.

\section{Resultados y discusión}

Composición proximal del jugo de jícama (piña, babaco y maracuyá)

Los resultados obtenidos del análisis físico - químico del jugo de jícama elaborado con diferentes frutas (piña, babaco y maracuyá), se reportan en la tabla 1.

Tabla 1. Análisis físico químicos del jugo de jícama con diferentes frutas

\begin{tabular}{|c|c|c|c|c|c|}
\hline \multirow{2}{*}{ Variables } & \multicolumn{3}{|c|}{ Jugo de jicama } & \multirow[t]{2}{*}{ Ee } & \multirow[t]{2}{*}{ Prob } \\
\hline & Piña & Babaco & Maracuya & & \\
\hline Ss, ${ }^{\circ}$ brix & $10,88 \mathrm{~b}$ & $9,32 \mathrm{c}$ & $11,50 \mathrm{a}$ & 0,1108 & 0,000 \\
\hline pH & $4,62 \mathrm{a}$ & $4,70 \mathrm{a}$ & $3,82 \mathrm{~b}$ & 0,0440 & 0,000 \\
\hline Acidez (\%) & $4,86 \mathrm{~b}$ & $4,74 \mathrm{~b}$ & $13,19 \mathrm{a}$ & 0,2453 & 0,000 \\
\hline Humedad, (\%) & $89,35 \mathrm{~b}$ & $90,26 \mathrm{a}$ & $89,23 \mathrm{~b}$ & 0,0858 & 0,000 \\
\hline Minerales, $(\%)$ & $0,51 \mathrm{~b}$ & $0,59 \mathrm{~b}$ & $0,78 \mathrm{a}$ & 0,0417 & 0,002 \\
\hline Calcio, (ppm) & $66,00 \mathrm{a}$ & $57.60 \mathrm{~b}$ & $46,20 \mathrm{c}$ & 0,6325 & 0,000 \\
\hline
\end{tabular}




\begin{tabular}{cccccc}
\hline Sodio, $(\mathbf{p p m})$ & $3,00 \mathrm{a}$ & $3,00 \mathrm{a}$ & $3,00 \mathrm{a}$ & ------- & ------ \\
Hierro, $(\mathbf{p p m})$ & $3,00 \mathrm{a}$ & $3,40 \mathrm{a}$ & $3,40 \mathrm{a}$ & 0,2000 & 0,300 \\
Proteína, $(\%)$ & $0,36 \mathrm{c}$ & $0,46 \mathrm{~b}$ & $0,54 \mathrm{a}$ & 0,0094 & 0,000 \\
Azucares $\mathbf{t},(\%)$ & $36,45 \mathrm{a}$ & $27.40 \mathrm{~b}$ & $38,62 \mathrm{a}$ & 0,6684 & 0,000 \\
\hline
\end{tabular}

Prob. $>0,05$, no existen diferencias significativas.

Prob. $<0,01$, existen diferencias altamente significativas.

Medias con letras iguales en la misma fila no difieren estadísticamente de acuerdo. a la prueba de Tuckey.

Fuente: Elaboración propia.

\section{Solidos Solubles, ${ }^{\circ}$ Brix}

Los resultados de los sólidos solubles ( ${ }^{\circ}$ Brix) de la bebida de jícama con diferentes frutas registraron diferencias altamente significativas $(\mathrm{P}<0.01)$, se observa que el tratamiento con la piña y babaco presentaron el menor contenido de sólidos solubles mientras que el tratamiento de maracuyá indica el mayor contenido de $11,50{ }^{\circ}$ Brix, podría atribuirse a que el maracuyá tiene de 12 a $14{ }^{\circ}$ Brix según lo señalado por (Castillo y Rojas 2005). Manifiestan que la fruta se degrada en azúcares solubles, principalmente glucosa, sacarosa, fructosa, siendo un elemento básico del adecuado e idóneo sabor. (Yucailla, 2016), señala que la jícama posee $12,2^{\circ}$ Brix lo que significa que es superior a la bebida formulada, considerando que se utilizó una mezcla de otros ingredientes lo que hizo posiblemente ocasiono la reducción de la concentración de sólidos.

$p H$

Las bebidas obtenidas presentaron diferencias altamente significativas en el análisis del $\mathrm{pH}$ por efecto de las diferentes frutas (piña, babaco y maracuyá) empleadas, por lo que se encontraron entre 4,62 y 4,70 en la bebida elaborada de jícama con piña y babaco respectivamente, siendo un $\mathrm{pH}$ acido no está dentro del rango según la norma NTE INEN 389 de Conservas vegetales, Determinación de la concentración del ion hidrógeno pH ya que indica que una bebida debe tener un $\mathrm{pH}$ menor a 4,5, sin embargo al utilizar Maracuyá se presentó un pH 3,82 que se encuentra en el rango permitido, de tal forma señala Castillo y Rojas que el maracuyá es más apreciado por la industria justamente por su $\mathrm{pH}$.

Según (Yucailla, 2016), manifiesta que la bebida de jícama posee un $\mathrm{pH}$ 7,30 que corresponde a neutro, valor superior a los registrados en el actual estudio, por esta razón se utilizó distintas frutas para disminuir el $\mathrm{pH}$ y así cumplir con lo dispuesto en la normativa nacional correspondiente.

Acidez Total 
La acidez titulable no es una medida de acidez total definida como la suma de ácidos presentes libres y combinados con cationes, sino una medida de cambios de concentración de ácidos orgánicos del fruto (Franson D., 2013). Por tanto, la acidez total presento diferencias altamente significativas al $(\mathrm{P}<0.01)$ por efecto del uso de diferentes frutas (piña, babaco y maracuyá), registrándose $13,19 \%$ de acidez total en la bebida de jícama con maracuyá, pero disminuyo notablemente a 4,86 y 4,74\% al mezclar con piña y babaco respectivamente. En otras palabras, el maracuyá es más ácido que la piña y el babaco, particularidad que hace que la bebida contenga mucha más acidez. En el trabajo de (Yucailla, 2016), muestra que la bebida de jícama posee una acidez de 0,16\% que prácticamente es baja siendo inferior a los registrados en este presente estudio, debiéndose principalmente a que usaron productos ácidos, los cuales además de poseer una propiedad antibacteriana que hacen que el producto sea resistente a la presencia de microorganismos.

\section{Agua.}

Se expresa el agua de la bebida elaborada a base de jícama con frutas presentaron diferencias altamente significativas a $(\mathrm{P}<0,01)$, por efecto de las distintas frutas utilizadas (piña, babaco y maracuyá), por esta razón, se encontró que al combinar jícama con babaco obtenemos 90,26\%, valor que difiere del contenido de agua de 89,35 y 89,23 $\%$ respectivamente de la bebida de jícama más piña y maracuyá, esto seguramente se compense a que el babaco concentra mayor cantidad de agua en su estructura que la piña y el maracuyá. Según (Yucailla, 2016, p. 28), La jícama posee 88,89 \% de agua característica que favorece a la elaboración de la bebida debido a que genera gran rendimiento en la obtención del zumo de la jícama, razón por la que se puede ingerir de manera directa como lo hacían en la antigüedad nuestros antepasados que usaban como fuente de hidratación y alimentación en sus largos viajes.

Cenizas, (\%)

$\mathrm{Al}$ analizar el porcentaje de cenizas de las bebidas obtenidas, las respuestas presentaron diferencias altamente significativas $(\mathrm{P}<0,01)$, por efecto de las diferentes frutas (piña, babaco y maracuyá) utilizadas, observándose la mejor respuesta al mezclar jícama con maracuyá registrando $0,78 \%$ de cenizas en base seca, siendo diferente a la utilización de piña y babaco puesto que registró 0,51 y $0,59 \%$ de cenizas, lo que significa que el maracuyá posee más minerales que la piña y babaco, razón por la que resulta importante en el equilibrio de la dieta de los consumidores. (Yucailla, 2016),(Sun 2015) reporta que la bebida hipocalórica registro 3,98\% de cenizas, determinándose que contribuye al valor nutritivo de la bebida puesto que los minerales que posee como el calcio y el hierro son necesarios para nuestro organismo, ya que nos ayudan en la construcción y mantenimiento de huesos y dientes, este valor es superior al registrado en el presente estudio, esto quizá se deba a que el porcentaje de cenizas que posee la bebida es en base húmeda y no en base seca como en este estudio. 
Calcio, sodio hierro (ppm)

Las respuestas del contenido de calcio de la bebida de jícama obtenidas presentaron diferencias altamente significativas (P 0,01), por efecto de las diferentes frutas (piña, babaco y maracuyá) utilizadas, pues se encontró que al utilizar jícama con piña fue de 66,00 ppm de calcio, valor que difiere de las bebidas de jícama con babaco y maracuyá que son de 57,60 y 46,20 ppm de calcio respectivamente, esto se debe a que la concentración de este elemento es más alto en la piña porque este cultivo es exigente en el calcio o a suelos alcalinos, lo que no ocurre con el cultivo de maracuyá y babaco tal como señala (Falconí. 2001), (Brito 2006).

(Arrobo, 2013), reporta que la jícama posee de 5 a $13 \mathrm{mg}$ de calcio lo que permite mencionar que el producto que se elabora por estar disuelto posee en menor cantidad este macro elemento fundamental en la dieta alimentaria.

Los resultados obtenidos en la bebida de jícama no registraron diferencias significativas $(\mathrm{P}>0,05)$, porque no hubo efecto al utilizar las diferentes frutas (piña, babaco y maracuyá) en la elaboración de la bebida de jícama, ya que registraron un contenido de 3 ppm de sodio, lo que significa que el contenido es bajo. El contenido de hierro de la bebida de jícama más la aplicación de piña, babaco y maracuyá fue de 3,00, 3,40 y 3,40 ppm respectivamente, valores entre los cuales no difieren significativamente $(\mathrm{P}>0,05)$, aunque se puede señalar que la utilización de babaco y maracuyá disponen de mayor cantidad de hierro, elemento fundamental en la sangre, razón por lo que las dietas alimenticias deben poseer en cantidades adecuadas para evitar problemas de anemia principalmente en los consumidores.(Cantillo, 2014)

\section{Proteína, (\%)}

La proteína determinada en la bebida nutritiva de jícama registraron diferencias altamente significativas ( $\mathrm{P}<0,01)$, por efecto de las diferentes frutas (piña, babaco y maracuyá) utilizadas, estableciéndose que al utilizar maracuyá en la bebida de jícama registro 0,54 $\%$ de proteína y disminuyó al utilizar piña y babaco, con los cuales se obtuvieron 0,36 y $0,46 \%$ de proteína, demostrándose de esta manera que estos frutos son escasos en compuestos nitrogenados por lo que estas bebidas son complementarias en la alimentación de los seres vivos.

De acuerdo a (Yucailla, 2016, p. 29), el zumo de jícama posee 3,73\% de proteína, siendo prácticamente alto al comparar con el presente estudio, esto puede verse afectado a que en el presente trabajo se utilizó otros ingredientes adicionales tales como piña, babaco y maracuyá que son pobres en compuestos nitrogenados y ricos en vitamina C razón por la que son ácidos lo que se corrobora con lo citado por (Mataíx, 2014) en cuanto a la composicón nutricional de diversos alimentos.

Azucares totales, (\%) 
Las bebidas nutritivas de jícama presentaron diferencias altamente significativas en el análisis de azúcares totales por efecto de las diferentes frutas (piña, babaco y maracuyá) utilizadas, se encontraron resultados de la bebida de jícama con maracuyá y piña de 38,62 y $36,45 \%$ de azucares totales, y disminuye al utilizar con babaco a un 27,40 \% de azucares totales. Para (Yucailla, 2016, Y Rifruco 2010), indican que el zumo de jícama posee alrededor de $19 \%$ de azucares totales. Valor inferior al registrado en el presente estudio, esto probablemente puede deberse al tiempo de exposición al sol de la jícama, puesto que mientras más es el tiempo de exposición al sol, este producto, la cantidad de azucares es más alto, esto se ha visto evidenciado de forma empírica la misma que requiere de un estudio exhaustivo, debido a que los almidones al someter a un medio especial como el calor, estos se transforman en carbohidratos simples, más conocidos como azucares.

\section{Análisis microbiológico}

Las bebidas de jícama con piña, babaco y maracuyá registraron ausencia de NMP/ml, los límites aceptables de este tipo de microorganismos sugeridos por la NTE INEN 1529-5 son $10 \mathrm{NMP} / \mathrm{ml}$.

\section{Conclusiones:}

- La composición nutricional del jugo de jícama formulado con maracuyá presentó las mejores características en cuanto a todos los parámetros físico químicos analizados principalmente sólidos solubles $11,50{ }^{\circ}$ Brix, $0,54 \%$ de proteína, 0,78 $\%$ de minerales totales y 38,62 \% azucares totales en relación a las otras dos formulaciones,

- La composición de macro minerales como Calcio 46,20 ppm y Hierro 3,40 ppm muestran mayor concentración de los mismos para la bebida de jícama formulada con maracuyá.

- Las tres formulaciones no presentaron microorganismo ajustándose así a la norma INEN NTE 2337 de Jugos, pulpas, concentrados, néctares, bebidas de frutas y vegetales para mesófilos, y coliformes.

- Se recomienda la industrialización de las tres formulaciones como alternativa para el mejor aprovechamiento de éstas frutas, además de las propiedades atribuídas a la jícama.

\section{Referencias bibliográficas:}

Alvarez, E. (2011). Centro Nacional de Tecnología Agropecuaria y Forestal. Obtenido de Guía Técnica del Cultivo de la Piña: Tomado de http://www.centa.gob.sv/docs/guias/frutales/GUIA\%20TECNICA\%20PIN\%CC $\% 83$ A\%222011.pdf . 
Arrobo, J. (2013). La fruta de jícama una alternativa de nutrición y salud. Obtenido de file:///D:/ANTEPROYECTO\%20JICAMA/48-191-1-PB\%20jicama.pdf. p. 25

Brito, D. 2006, "EL BABACO." Tomado de http://www.sica.gov. pp. 11-15

Cantillo, B. (2014). A comer frutas y vegetales. Nutrición. Obtenido de Fundación Bengoa para la Alimentación y Nutrición: Obtenido de: http://www.fundacionbengoa.org/informacion_nutricion/comer_frutas_vegetales .asp

Castillo, M y Rojas, P. (2005). Determinación de las Propiedades en Zumo y Néctar Empleados en un Programa en Visual Basic. Chimbote - Perú. Pp.16,18

Diaz, P. (2015). Frutas tropicales: Elaboración de pulpas, jugos y deshidratados. Obtenido de cuaderno tecnológico. Edición 12: pp. 20-25 Tomado de https://inti.gob.ar/ue/pdf/publicaciones/cuadernillo12.pdf. pp. 15

Franson D, (2013), Industria de las Bebidas Enciclopedia de la Salud y la Seguridad en el Trabajo.

Recuperado de: http://www.insht.es/InshtWeb/Contenidos/Documentacion/TextosOnline/Encicl opediaOIT/tomo3/65.pdf

Falconí., C. (2001), Babaco, Mountain Papaya (Carica Pentagona). C. M. Iica. Quito. pp. 16

Instituto Ecuatoriano De Normalización. 2008. NTE-INEN 2337,. Ecuador. Jugos, pulpas, concentrados, néctares, bebidas de frutas y vegetales. Obtenido de http://normaspdf.inen.gob.ec/pdf/nte/2337.pdf

Instituto Ecuatoriano De Normalización 2006. Ecuador, NTE INEN 1529-5. Control microbiológico de los alimentos. Determinación de la cantidad de microorganismos aerobios mesofilos. Obtenido de Instituto Ecuatoriano de Normalización: Recuperado de: http://archive.org/stream/ec.nte.1529.5.2006\#page/n1/mode/2up

Instituto Ecuatoriano De Normalización Ecuador. 2013. NTE INEN 1529-6. Control microbiológico de los alimentos. Determinación de microorganismos coliformes por la técnica del número más probable. Obtenido de Instituto Ecuatoriano de Normalización: Recuperado de: http://www.normalizacion.gob.ec/wpcontent/uploads/downloads/2014/NORMAS_2014/ACO/17122014/nte_inen_iso _4831_ext.pdf

Instituto Ecuatoriano de Normalización. Ecuador. 2013. NTE INEN 1529-10. Control microbiológico de los alimentos. Mohos y levaduras viables. Recuento en placas por siembra en profundidad. Obtenido de Instituto Ecuatoriano de Normalización.

Recuperado de: http://www.normalizacion.gob.ec/wpcontent/uploads/downloads/2014/NORMAS_2014/ACO/17122014/nte-inen1529-10-1r.pdf

Manrique, I., Párraga, A. y Hermann, M., (2003), Jarabe de Yacón: Principios y procesamiento, Centro Internacional de los frutos. Perú. pp. 3 - 8. 
Mataix, J. (2012). Universidad de Granada. Obtenido de Tabla de Composición de Alimentos Española.

Tomado

de:

file://C:/Users/J.J/Downloads/pina2.compressed.pdf

Parrilla, P. 2002. A través de los sentidos. Revista Enfasis Alimentacion en Latinoamerica. Agro VIII. Tercera Edicion. Pp 12-15

Rifruco, 2010. Información sobre el Babaco. Valor Nutricional del Babaco: Tomado de http://rifruco.blogspot.com/p/informacion-de-la-fruta.html. pp. 17

Rojas,M. (2001), Ascorbic acid destruction in aqueous model systems: an additional discussion. J. Sci. Food AAgric. 81: 1433-1439

Sun, M. (2015). Nutritional Composition of Fruit Cultivars. Obtenido de Nutritional Composition of Pineapple Tomado de: http://www.sciencedirect.com/science/article/pii/B9780124081178000258

Yucailla, S. (2016). Desarrollo y Evaluación de una bebida hipocalórica apta para diabéticos a base de zumo de Jícama (Smallanthus sonchifolius). Tesis de pregrado. Escuela Superior Politécnica de Chimborazo. Facultad de Ciencias. Riobamba - Ecuador. pp. 26-38 


\section{PARA CITAR EL ARTÍCULO INDEXADO.}

\section{Baño Ayala, D. J., Velasco Gómez, J. L., López Sampedro, S. E., \& Arboleda Alvarez ,} L. F. (2020). Estudio comparativo de tres bebidas formuladas con jícama (Smallanthus sonchifolius). ConcienciaDigital, 3(3), 141-150.

https://doi.org/10.33262/concienciadigital.v3i3.1286

\section{Ligital}

El artículo que se publica es de exclusiva responsabilidad de los autores y no necesariamente reflejan el pensamiento de la Revista Conciencia Digital.

El artículo queda en propiedad de la revista y, por tanto, su publicación parcial y/o total en otro medio tiene que ser autorizado por el director de la Revista Conciencia Digital.
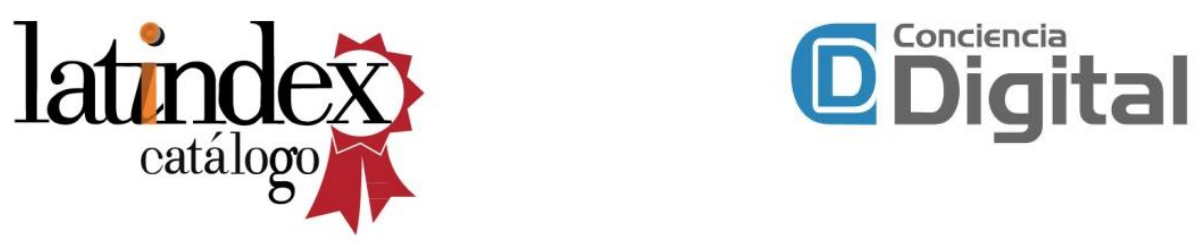